\title{
Uma estrutura de classificação com enfoque na cultura amazônica
}

\author{
Anderson Rodrigues \\ Bibliotecário graduado pela Universidade Federal do Pará \\ E-mail: andersonlcr@hotmail.com
}

\section{INTRODUÇÃO}

O homem amazônida vive em profunda relação de harmonia com a natureza que o cerca, o que gera fecunda produção de imaginário próprio, emoldurado por uma espécie de sfumato que se instaura como uma zona indistinta entre o real e o surreal, onde os rios e as florestas tornam-se muito importantes para esse cotidiano. A Amazônia é também uma região de riquezas no que tange à fauna e flora (biodiversidade), riqueza à qual cada vez mais o mundo direciona o seu olhar. Assim, este trabalho focaliza um aspecto igualmente importante, mas não tão salientado por esses tais "olhos do mundo": o âmbito cultural amazônico.

Em meio a esse ambiente complexo e enigmático, o projeto Resnapap (A Representação Simbólica das Narrativas Populares da Amazônia Paraense), do Departamento de Biblioteconomia da Universidade Federal do Pará, sob coordenação da professora doutora Maria Odaisa Espinheiro de Oliveira, propôs-se a elaborar uma linguagem de informação, ou mais especificamente um tesauro, a partir do universo cultural da Amazônia paraense.

Em 1941, o escritor paraense Dalcídio Jurandir produz a belíssima obra Chove nos Campos de Cachoeira, premiada por dois dos maiores prêmios da literatura nacional*. Nela, retrata de maneira magnífica a vida, os costumes, o modo de sentir e pensar do povo amazônida. Assim, decidimos realizar a difícil tarefa de elaborar uma estrutura de classificação a partir do que o projeto concebe como termo cultural, sendo este elemento coletado mediante a obra de Dalcídio. O objetivo fundamental deste trabalho consiste, sobretudo, em dar suporte para a construção do futuro tesauro.

O Resnapap está em andamento na Universidade Federal do Pará (UFPA) desde 1998, e iniciou suas atividades como subprojeto do projeto Ifnopap (O Imaginário nas Formas Narrativas Orais Populares da Amazônia Paraense), do Centro de Letras e Artes da mesma

\footnotetext{
* Dalcídio Jurandir teve sua primeira obra premiada em 1941 pela editora Vecchi, em conjunto com o jornal Dom Casmurro. Nesse mesmo prêmio, Dalcídio obteve a primeira colocação com Chove nos Campos de Cachoeira e o quarto lugar, sob pseudônimo, com a obra Marinatambalo, que depois viria a denominar-se Marajó. Em 1972, ganha o prêmio Machado de Assis pelo conjunto de obras, conferido pela Academia Brasileira de Letras.
} 
instituição. Durante vários anos utilizou as narrativas orais populares do acervo do projeto Ifnopap com o intuito de coletar o que se denominou termo cultural. Estudadas as 11 áreas de abrangência do acervo do Ifnopap, o Resnapap, em um segundo momento, começa a trabalhar com outro tipo de documento, ou seja, com as narrativas da literatura paraense, e não mais com textos de cunho oral. Uma dessas narrativas foi a obra Chove nos Campos de Cachoeira, de Dalcídio Jurandir.

\section{O TERMO CULTURAL: A UNIDADE CONCEI- TUAL DO SISTEMA DE CLASSIFICAÇÃO}

O termo cultural é a unidade conceitual que irá compor a estrutura de classificação. Sob o ponto de vista da cultura, o projeto Resnapap entende este como a representação simbólica do universo cultural no qual um indivíduo está inserido, e, sob a égide da lingüística, pode ser visto como a unidade lexical da linguagem natural do homem amazônico (OLIVEIRA; RODRIGUES; MOYSÉS, 2003a).

Como parte da língua, é um instrumento para comunicar a realidade física e cultural do povo que a usa. Quando o homem utiliza a fala ou a escrita para transmissão de sua cultura, os termos passam a ser portadores de informação sobre a cultura [...], representando uma forma de saber (OLIVEIRA et alii 2003b).

Desse modo, sendo um portador de informação acerca da cultura de quem o usa, o termo cultural pode nos revelar aspectos relevantes do modo de vida, dos costumes, das crenças, assim como da maneira de ver as coisas à sua volta; no caso deste estudo, do homem marajoara.

\section{POR QUE DALCÍDIO JURANDIR E SUA OBRA?}

Após termos uma noção acerca do termo cultural, podemos, agora, melhor entender o motivo pelo qual o projeto Resnapap escolheu a obra de Dalcídio Jurandir, escritor que muito escreveu sobre a terra onde nasceu e viveu boa parte de sua vida. Vejamos alguns fatores que levaram o escritor a ser escolhido como material para a pesquisa.

Como o projeto Resnapap se encontrava em momento de transição, a transposição do tipo de documento (narrativa oral para narrativa culta) deveria ser feita a partir de um texto de cunho culto que se aproximasse ou se intercalasse com a forma literária do texto oral. Então, a escolha da obra Chove nos Campos de Cachoeira, de Dalcídio Jurandir, foi pertinente, haja vista que alguns estudiosos deste autor sugerem esta aproximação, defendendo que as narrativas dalcidianas confundem-se entre o ficcional e o real.

Fares (2004) chega a equivaler os textos de Dalcídio ao nível oral. A autora concluiu essa idéia mediante informações coletadas junto aos moradores, parentes e amigos do escritor, quando em uma visita à cidade onde o autor viveu (município de Cachoeira do Arari, Pará), constatando que muitos personagens e cenários contidos na obra de fato existiram. Nunes (2002) acrescenta: "O autor não esqueceu as raízes da tradição narrativa oral popular e, vez em quando, abre, em seus textos, espaço para os contadores de história do Marajó-berço".

Outro fator bastante relevante que nos levou a trabalhar com Dalcídio Jurandir é por ele ter nascido na região e morado grande parte de sua vida na Amazônia, uma vez que isso facilitaria o uso intensivo de termos peculiares e correntes da cultura regional em seus textos. Conseqüentemente, dava-nos o ensejo de coletar os termos culturais visando à composição do corpus terminológico do futuro tesauro cultural amazônico. Pelo viés do conhecimento empírico da realidade amazônica, Dalcídio Jurandir possuía íntima relação com o universo relatado em sua obra.

Fui menino de beira-rio, do meio do campo, banhista de igarapé. Passei a juventude no subúrbio de Belém, entre amigos nunca intelectuais, nos salões da melhor linhagem que são os clubinhos de gente da estiva e das oficinas, das doces e brabinhas namoradas que trabalhavam na fábrica. Um bom intelectual de cátedra alta diria: são as minhas essências, as minhas virtualidades. Eu digo tão simplesmente: é a farinhad'água dos meus beijus. Sou também de lá, sempre fiz questão de não arredar pé de minha origem e para isso, ou melhor, para enterrar o pé mais fundo, pude encontrar uma filiação ideológica que me dá razão. Os temas dos meus romances vêm do meio daquela quantidade de gente das canoas, dos vaqueiros, dos colhedores de açaí. Uma das coisas que eu considero válidas na minha obra é a caracterização cultural da região. Acumulei experiências, pesquisei a linguagem, o falar paraense, memórias, imaginação, indagações. Para um escritor pobre, que vende de mil a mil e quinhentos exemplares, sem vagares e ócios remunerados, o esforço é, às vezes, de desesperar, de tão braçal e tão de graça, mas é ao mesmo tempo uma delícia, uma forma de satisfeita revolta contra o magro pão, o sucesso fácil, a cômoda posição pessoal no mundinho (JURANDIR, 1976, apud TORRES; MARANHÃO; GALVÃO, 1996, p. 29). 
Nunes (2004, p. 18) comenta que Dalcídio Jurandir utiliza tanto "termos locais ou regionais, [...] quanto expressões coloquiais", além de "nomes regionais de árvores, ervas, velas, mastros, cordames de barco [...] diversificadas expressões: vocativa (meã filha), exclamativa, de repulsa ou asco (axi!), diminutivas (iazinho, descerzinho)" ou outras várias palavras que o romancista pode ter inventado, "apoiando-se no imaginário lingüístico da região". Desse modo, como podemos perceber, a obra circunscrita neste estudo proporciona rico manancial de unidades conceituais de grande interesse para a presente pesquisa*. Segundo Nunes (2001, p. 21), nas narrativas dalcidianas se encontra "o mais profundo painel sobre a região amazônica que a ficção literária poderia produzir neste século XX".

Outro motivo, porém mais sutil, utilizado para a escolha da obra se baseia no recurso literário que o escritor utilizou, ao qual Nunes (2004, p. 19) chama de "introspecção", ou seja, a reflexão do personagem consigo mesmo ou a manifestação de sua visão do mundo verbalizada em suas experiências subjetivas. Esse olhar que se origina no interior dos personagens propicia a expressão do imaginário da cultura local, que é processado conjuntamente conforme o conhecimento cognitivo acerca dos costumes regionais do escritor. Ao utilizar esse recurso literário de influência proustiana, Jurandir pretende evidenciar as "reflexivas reações aos acontecimentos" (NUNES, 2004, p. 19) dos personagens; entretanto, acaba por exteriorizar o peculiar vocabulário regional como forma de reforçar o ambiente próprio amazônico.

\section{O SISTEMA DE CLASSIFICAÇÃO: UMA COLABORAÇÃO PARA A CONSTRUÇÃO DO FUTURO TESAURO}

A delimitação do universo de assunto é inerente a um tesauro, pois sistematiza conceitos "de uma área de assunto", e, segundo Gomes (1996b), "não se pode falar de um tesauro geral, mas de tesauros especializados". Assim, os tesauros são sistemas artificiais de signos normalizados com o objetivo de recuperar manual ou automaticamente a informação que o usuário solicita. Na definição de Tristão (2004), é um conjunto de

\footnotetext{
* É válido lembrar que esse aspecto regionalista da obra dalcidiana é o que mais nos interessou neste trabalho, mas os estudiosos desse autor costumam enfatizar a faceta universalista intrínseca em seus textos. Dalcídio Jurandir é considerado, por muitos, como um revolucionário no que tange ao tratamento da literatura em relação à Amazônia. Ele desnuda as almas dos habitantes amazônidas, em detrimento de não dar a ênfase maior ao ufanismo. Desse modo, em suas obras, o sentir do homem amazônico não é subjugado nem sobreposto à fauna ou a flora dessa região.
}

conceitos organizados sistematicamente para fins de indexação e recuperação. A estrutura trabalhada aqui visa a colaborar de forma parcial para a construção do futuro tesauro proposto pelo Resnapap.

Um fator interessante a se destacar é que, com a elaboração da estrutura de classificação e, posteriormente, do tesauro, estaremos contribuindo também para a preservação da memória cultural da Amazônia paraense. Guimarães (2000), apud Tristão, (2004) ressalta a dimensão cíclica da organização e destaca o conhecimento em ação, que, quando organizado e registrado, passa a ter uma perspectiva de geração de novo conhecimento. Na medida em que é registrado e divulgado, passa a ser informação, reiniciando um círculo contínuo. Dobedei (2002), apud Tristão (2004), reforça a questão e apresenta o modelo ao qual denominou "Ciclo da Informação" ou modelo de "Transferência da Informação", apresentando-o em seis etapas: produção, registro, aquisição, organização, disseminação e assimilação. Segundo essa autora, no processo de transferência da informação, os instrumentos de organização do conhecimento vêm colaborar na preservação da memória social; assim, incorporam no modelo o "conceito de memória documentária" (TRISTÃO, 2004, p. 162).

O objetivo de uma estrutura de classificação, tal como de um tesauro, é representar o conhecimento de forma organizada para que se possa recuperar a informação de maneira mais ágil. O próprio termo "representar" nos remete à abstração, ou melhor ainda, abstração da realidade. Um termo é um signo no qual o homem tentou representar a maneira mais aproximada de um objeto que ele observou na realidade empírica. Assim, após a percepção, ele designa sinteticamente o conceito junto com o seu conjunto de característica, que se convencionou chamar de termo. Davis (1992), apud Campos (2001, p. 49), ressalta que a representação do conhecimento é um "substituto para aquilo que representa" e destaca dois aspectos fundamentais: quanto à semântica da representação e quanto à fidelidade perfeita, e, segundo o autor, tanto na prática quanto em princípio, esse fato é impossível. "A única representação completamente precisa de um objeto é o objeto em si. Qualquer outra representação é imprecisa e, inevitavelmente, contém simplificações". De acordo com o mesmo autor, a representação do conhecimento não passa de uma aproximação imperfeita da realidade. Ele comenta que a complexidade do mundo real é esmagadora em relação à representatividade do conceito. 


\section{Anderson Rodrigues}

A Teoria Geral da Terminologia defende que, ao perceber a realidade, o homem realiza a construção mental de um objeto e, ao observar a realidade que o cerca, acaba por perceber objetos individuais, partes desse todo, que nela estão inseridos. Essas particularidades podem ser a cor, o tamanho, uma ação etc., que constituem a característica do conceito (CAMPOS, 2001).

Depois de se identificar a unidade classificatória (termo cultural) da narrativa trabalhada, um passo significativo para estruturar o sistema de classificação foi definir os termos culturais. É a partir desta etapa que podemos conhecer as características do conceito, pois elas são o principal elemento de ligação ou separação no momento da formação das classes.

Morin (2000, p. 24) afirma que toda organização de conhecimento é realizada em função de princípios e regras e "comporta operações de ligação (conjunção, inclusão, implicação) e de separação (diferenciação, oposição, seleção, exclusão)", além de comportar análise e síntese concomitantemente. Dahlberg (1978) salienta que a definição é um recurso utilizado para dirimir dúvidas no uso do termo, e mais que isso, possibilita, além da fixação do conceito, seu posicionamento no próprio sistema de conceitos. A Teoria do Conceito de Dahlberg não vê a definição em segundo plano, mas como um recurso para estabelecer as fronteiras da intensão do conceito. Para essa teoria, as características servem para entender a natureza e a abrangência do conceito, além de serem responsáveis pela formação da estruturação sistêmica conceitual. Nesse sentido, elas fornecem, ao mesmo tempo, o esqueleto, os ossos e os tendões para sistematizar o conhecimento (CAMPOS, 2001; TRISTÃO, 2004; DAHLBERG, 1978)

Quanto ao número de características que abrangem um conceito, chama-se intensão* para conjunto de características que constituem o conceito, e, quanto maior for o agregado, mais específico será; por conseguinte, quanto menor for, mais geral ele será (GOMES, 1996b). As características são usadas como princípio para divisão e comparação dos elementos classificatórios, objetivando estruturar o sistema a partir da formação das classes e, dentro destas, os renques e as cadeias. Langridge $(1977$, p. 24) comenta que as características de divisão "devem produzir no mínimo duas classes".

\footnotetext{
* "Intensão" está relacionada ao conceito, diferentemente de "intenção", que está relacionada à vontade, desejo.
}

Renques (array) e cadeias (chain) são denominações dadas por Ranganathan para diferenciar, na formação de classes, séries horizontais (renques) - a partir de uma única característica de divisão - e verticais (cadeias) de conceitos - em que cada conceito tem uma característica a mais (descendente) ou a menos (ascendente). No exemplo a seguir, extraído do sistema de classificação elaborado, a título de visualização, veja como os conceitos Caroço de Tucumã e Miriti formam um renque e os conceitos Arte, Artesanato, Matéria-Prima e Caroço de Tucumã formam uma cadeia entre si.

Ex: ARTE

\section{ARTESANATO MATÉRIA-PRIMA CAROÇO DE TUCUMÃ MIRITI}

Utilizando o exemplo anterior, podemos perceber que há uma relação de subordinação que se dá entre os conceitos Arte e o conceito Artesanato, onde "Arte" é o conceito superordenado, também chamado de genérico, em relação à "Artesanato", que é o conceito subordinado, também chamado de específico. Quando eles estão no mesmo nível hierárquico, como é o caso do conceito "Caroço de Tucumã" em relação ao "Miriti", eles são denominados conceitos coordenados. É interessante salientar o relativismo conceitual, pois o conceito deve ser olhado a partir de um dado ponto no espaço sistêmico. Ele é identificado mediante um ponto de referência espacial; o conceito só é específico, genérico, relacionado, subordinado ou coordenado em relação a outro elemento que também se encontra inserido no sistema. Esse processo pode ser percebido nos tesauros, pois eles mostram as relações de um conceito com os outros mais próximos.

Para a Teoria da Classificação Facetada de Ranganathan, as unidades conceituais do sistema são concebidas como assunto básico e idéia isolada. Assim, tal como na Teoria Geral da Terminologia, de W. Eüster, nesta teoria acredita-se que os conceitos estão interligados e dependentes uns dos outros. Para Langridge (1977, p. 56), a expressão usada por Ranganathan, "assunto básico", significa qualquer área do conhecimento na qual uma pessoa pode se especializar. $\mathrm{O}$ assunto básico representa as áreas abrangentes do conhecimento (TRISTÃO, 2004), ou seja, é um assunto sem nenhuma idéia isolada como componente (CAMPOS, 2001), como, por exemplo, Matemática, Sociologia, Biologia, Física, Cultura. Já a idéia isolada é definida como "alguma idéia ou complexo de idéias ajustadas para formar um 
componente de um assunto, mas, em si mesma, ela não é considerada um assunto" (CAMPOS, 2001, p. 55). Ela forma um componente específico de um assunto e funciona como uma unidade combinatória, chamada, por isso, de especificadora por alguns autores.

Loureiro (2001, p. 42), quando se refere à cultura amazônica, afirma que esta é dinâmica, original e criativa, haja vista que revela, interpreta e cria sua realidade. Assim, diante desse universo temático, os assuntos básicos surgidos não são nada mais, nada menos que as diversas manifestações preservadas ao longo da história peculiar do homem amazônico, tanto no que refere aos aspectos materiais (como os meios de transportes utilizados, a fauna, a flora, a culinária típica etc.) quanto aos aspectos não-materiais (os mitos, as expressões artísticas, a religião etc.).

Ranganathan (1967), ao criar o chamado Postulado das Categorias, determina que o primeiro passo do classificacionista para elaborar uma estrutura de classificação é mapear o que ele chamou de Universo de Assuntos. Esta atividade tem por função definir o nível de extensão deste universo. Este mapeamento consiste em se decidir a área de assunto que será tomada como base para a organização das unidades classificatórias e como esta área será classificada. Segundo o próprio autor, esta atividade é uma tarefa bastante complexa:

Podemos perder noites de sono e ainda não estarmos perto de uma solução firme. Se não formos estudantes sérios de classificação, podemos desistir dizendo 'a classificação é impossível'. Para uns poucos a classificação é mesmo marcada por um absurdo lógico. Esta é a medida da magnitude do mapeamento do Universo de Assuntos multidimensional ao longo da atividade que é a classificação (RANGANATHAN, 1967, p. 395).

Desse modo, pode-se perceber quão difícil é mapear o Universo de Assunto, e Langridge (1977, p. 34), adotando a mesma opinião, comenta que o classificacionista deve explorar ao máximo o detalhamento de divisão do conhecimento. Afirma que esse processo se torna mais fácil em disciplinas como Física, Química, Biologia; mas, quando se trata de disciplinas menos exatas, como Filosofia, História, Arte e outras, a dificuldade é maior em função do domínio dos objetos classificados, tarefa esta que seria dos filósofos (WOJCIECHOWSKI, 1974, apud POMBO, 1988). "O bibliotecário que é bibliotecário não é um perito sobre o universo do conhecimento: este é o campo dos filósofos, dos cientistas e dos historiadores" (LANGRIDGE, 1977, p. 34). Assim, não seria diferente quando se trabalha com o universo de qualquer cultura. Também nos diz Wojciechowski (1974, p. 14), apud Pombo (1988, p. 13)

para o classificacionista, o que está em causa na apreciação do valor de uma classificação é a sua utilidade prática, a rapidez, exactidão e facilidade da sua utilização, para o filósofo, o problema da classificação é sempre, em última análise, um problema de adequação, isto é, de conformidade entre a classificação e o domínio de objectos classificados (WOJCIECHOWSKI, 1974, p. 14, apud POMBO, 1988, p. 31)

Diante disso, Ranganathan (apud CAMPOS, 2001) postula que, em todo Universo de Assunto, existem cinco idéias fundamentais (PMEST - Tempo, Espaço, Energia, Matéria e Personalidade, iniciais em inglês) que são utilizadas para a divisão desse universo. A essas idéias ele chamou Categorias Fundamentais, as quais permitem recortar o Universo de Assunto em classes bastante abrangentes. Essas categorias funcionam como o primeiro corte nesse universo. No caso deste estudo, o universo cultura amazônica foi recortado em 11 categorias (ver tabela 2) e o projeto Resnapap denominou-as Categorias de Assunto.

Como Ranganathan percebe que o conhecimento está sempre em desenvolvimento contínuo, ou seja, que o universo do conhecimento é, sobretudo, dinâmico, ele propõe uma nova forma de organizar o universo de assunto. Sugere que a organização do conhecimento seja representada pela da Árvore Baniana e não mais pela Árvore de Porfírio. Durante muitos séculos esta última se mostrou satisfatória; porém, desde a década de 20 do século XX, esse tipo de representação não mais supria as necessidades no âmbito da classificação. A Árvore de Porfírio foi idealizada por Aristóteles e constitui-se como um conjunto hierárquico finito de gêneros e espécies, que funciona por dicotomias sucessivas. $\mathrm{O}$ esquema dicotômico procede do geral ao particular, da maior extensão à maior compreensão, do gênero à species ínfima (POMBO, 1988). Apesar de Perelman (1963), apud Pombo (1988), acreditar que as dicotomias são "as classificações logicamente mais satisfatórias", Ranganathan propõe uma classificação a partir de policotomias ilimitadas, principalmente porque a produção do conhecimento passa a se tornar mais intensa nos últimos anos. Em relação ao problema da Árvore de Porfírio, Buffon (1749), apud Pombo (1988, p. 27), no século XVIII já previa:

a natureza caminha por gradações desconhecidas e, por conseqüência, ela não se pode prestar totalmente 


\section{Anderson Rodrigues}

a essas divisões, uma vez que ela passa de uma espécie a outra, e muitas vezes de um gênero a outro, por nuances imperceptíveis, de tal forma que se encontra um grande número de espécies intermédias e de meios-objectos que não sabemos onde colocar e que pertubam necessariamente o projecto de um sistema geral (BUFFON, 1749, p. 3, apud POMBO, 1988, p. 27).

Na Árvore Baniana, do tronco original formam-se outros secundários, conforme a produção do conhecimento vai se expandindo. Os conceitos se relacionam não mais somente a um núcleo/ raiz, mas a diversos núcleos, diferentemente da Árvore de Porfírio, que falha quando, nos dias atuais, percebe-se que o conhecimento não faz parte de um só domínio, pois eles são complexos e se relacionam de várias maneiras. Dessa forma, a cultura amazônica se adapta, a nosso ver, aos moldes da Árvore Baniana, uma vez que os termos culturais vivem em fluxo contínuo, principalmente com a tendência de integração da região no âmbito nacional e mundial. Novos termos surgem e outros desaparecem proporcionalmente ao movimento desta sociedade.

Pensando no dinamismo do universo do conhecimento, Ranganathan elabora dois cânones como princípios para pensar a formação de classes de conceitos: a exaustividade e a exclusividade. No cânone exaustividade, ele estabelece que as classes formadas devam ser exaustivas, de maneira que, se algum conceito novo surgir, deve ser acrescentado à estrutura, e esta precisa ter hospitalidade para agrupá-lo em uma classe existente. Já no cânone exclusividade, Ranganathan estabelece que as classes formadoras dos renques devam ser mutuamente exclusivas, ou seja, nenhum conceito da estrutura pode pertencer a mais de uma classe no renque. Desse modo, o autor não aceita poli-hierarquia (CAMPOS, 2001).

\section{METODOLOGIA}

Neste estudo não houve a utilização de um único método; conjuminaram-se vários, devido ao seu caráter técnicopragmático. A análise de conteúdo predominou quanto à análise do conteúdo do conceito, pois houve a necessidade de conhecê-lo para que fosse possível inserilo na estrutura de classificação de acordo com seu posicionamento adequado dentro do sistema. No entanto, para conhecê-lo foi necessário utilizar a descrição analítica, que funciona segundo "procedimentos sistemáticos e objectivos de descrição do conteúdo" (BARDIN, 1977, p.34), que, no caso desta pesquisa, refere-se ao conteúdo do conceito, ou seja, a definição, na qual é elucidado o conjunto das características. No que diz respeito à classificação propriamente, utilizou-se a análise categorial, método taxionômico concebido para "satisfazer os coleccionadores preocupados em introduzir uma ordem, segundo certos critérios, na desordem aparente" (BARDIN, 1977, p.37), assim como para referenciar regras de associação, de equivalência, ou ainda de exclusão.

Portanto, para que fosse possível chegar à elaboração da estrutura de classificação proposta neste estudo, alguns passos foram imprescindíveis e antecederam tal atividade.

O primeiro passo realizado foi ler a obra Chove nos Campos de Cachoeira, de Dalcídio Jurandir, com o propósito de coletar o termo cultural mediante a identificação e análise do mesmo. Coletados os termos, foi necessário registrá-los. Assim, foi criada pelo Resnapap uma ficha terminológica baseada em um modelo proposto por Faulstich (1995), adaptada conforme as necessidades do projeto. A estrutura da ficha foi composta das seguintes informações: a) termo; b) categoria gramatical; c) gênero; d) sinonímia; e) categoria do termo; f) variante gráfica; g) fonte da variante gráfica; h) variante geográfica; i) fonte da variante geográfica; j) definição; k) fonte da definição (de onde se extraiu a definição); l) contexto (da narrativa, em que se coletou o termo); m) narrativa; n) autor; o) remissiva.

Para o preenchimento dos termos nas fichas terminológicas, os mesmos deveriam se enquadrar obedecendo à seguinte orientação:

- Cada termo sua ficha, exceto quando forem observados casos de polissemia. Este fato ocorre porque, mesmo que o termo seja equivalente, possui um referente ou um conceito diferente; desse modo, ambos poderão ser englobados em classes ou categorias distintas.

- Os termos equivalentes devem ser controlados por meio dos campos sinonímia, variação gráfica ou variante geográfica (quando aparecerem oscilações no que diz respeito aos termos usados de diferentes maneiras em regiões diferentes). Esse fenômeno vai auxiliar no relacionamento de equivalência na estrutura de classificação. Esta relação ocorre entre o termo preferido e o não-preferido, onde dois ou mais termos são considerados, para fins de indexação, como referentes do mesmo conceito, apesar da distinta grafia. As relações de equivalência em um sistema de classificação podem ser explicitadas pelos pontos de entrada "Use", "Usado para", "Ver", "Ver também" e "Veja". 


\section{Ex: CUPUAÇUAZEIRO \\ Cacau-da-nova-granada \\ UP Cacau-da-nova-granada USE CUPUAÇUZEIRO}

- Os termos não peculiares do universo cultural amazônico não devem ser registrados nas fichas terminológicas.

- O campo Definição deve ser preenchido de acordo com o contexto da narrativa, a menos que na narrativa o autor não deixe claro quanto ao conteúdo do termo.

Outrossim, foram feitas as definições dos termos culturais. Esta etapa constituiu uma das mais importantes, haja vista que, a partir da definição, pôdese conhecer as características dos termos/conceitos, sendo possível fixar cada termo em suas posições apropriadas dentro da estrutura de classificação. Conforme afirma Campos (2001), só se pode elaborar uma estrutura de classificação após a definição das unidades que constituem o sistema, pois é a partir da definição dessas unidades que serão elucidadas suas características, uma vez que os conceitos são agrupados ou classificados conforme suas características comuns. A definição deveria ser realizada de acordo com o contexto da narrativa; no entanto, quando o autor não deixou claro quanto ao conteúdo do termo, foi necessário recorrer às obras lexicográficas (dicionários, vocabulário terminológico, repertório de termos etc.) para nortear o desenvolvimento desta tarefa.

Depois de definidos os termos, realizaram-se com mais precisão a análise e a seleção do termo cultural, uma vez que, neste momento, já se obtinha o domínio da extensão do conceito. Por fim, realizou-se a etapa da classificação dos termos culturais.

Na etapa da classificação dos termos, inicialmente, criouse o que Ranganathan (1967) chamou de Categorias Fundamentais, usadas pelo autor para "representar idéias fundamentais que permitem recortar um Universo de Assunto em classes bastante abrangentes". Ou seja, foram criadas classes abrangentes que pudessem comportar grande número de subclasses e hierarquias subordinadas a estas classes maiores. Criadas as Categorias Fundamentais, deu-se início ao processo das ramificações e das relações dos conceitos que se encontrariam no interior das macroclasses. Desse modo, ocorreu o processo de formação dos renques e, posteriormente, foram realizadas as relações de equivalência e de associação.

Ranganathan, apud Campos (2001), observa que, ao se elaborar um sistema de classificação, o elaborador deve atentar para o fato de que, no momento de formação das classes, é importante ter em mente o cânone
Exclusividade. Contudo, em alguns casos, esse fenômeno foi impraticável, visto que pequeno número de conceitos tinha ligações ou vínculos com classes distintas. Em outras palavras, esse conceito abrangia mais de uma função na cultura amazônica. Veja o exemplo do termo extraído do sistema de classificação elaborado nesta pesquisa: Miriti. Ele tanto é um elemento da flora, quanto matéria-prima utilizada no artesanato amazônico:
ARTE

TE ARTESANATO MATÉRIA-PRIMA MIRITI

\section{TE FLORA}

ÁRVORE

PALMAS

MIRITI

\section{BIOLOGIA}

Conforme já exposto, outro ponto importante que Ranganathan destaca na elaboração de uma estrutura de classificação é quanto ao cânone Exaustividade. No entanto, neste estudo, só se trabalharam os conceitos/ termos coletados da obra Chove nos Campos de Cachoeira, de Dalcídio Jurandir, isto é, a formação das classes derivou exclusiva e unicamente das características encontradas nesses termos culturais; assim, não se criaram classes sem unidades conceituais para se agregar, com o intuito de possível alimentação futura. Todavia, na ocasião em que o tesauro for definitivamente construído, haverá maior número de unidades conceituais a serem trabalhadas, haja vista que existirão mais termos coletados mediante outras narrativas.

\section{RESULTADO}

A partir da leitura do romance Chove nos Campos de Cachoeira, identificaram-se 605 termos culturais. Todavia, somente 512 termos foram selecionados e registrados na ficha terminológica após serem analisados na etapa de definição, conforme pode ser visualizado na tabela 1 .

TABELA 1

Termos culturais coletados na obra Chove nos Campos de Cachoeira, de Dalcídio Jurandir

\begin{tabular}{l|c|c}
\hline & Total & Percentual (\%) \\
\hline Termos culturai s identificados & 605 & 100 \\
\hline $\begin{array}{l}\text { Termos culturais selecionados } \\
\text { e definidos }\end{array}$ & 512 & 84,628 \\
\hline
\end{tabular}

Fonte: Projeto Resnapap. 
TABELA 2

Quantidade de unidades conceituais por categoria de assunto.

\begin{tabular}{l|c|c}
\hline Categorias de Assunto & $\begin{array}{c}\text { Quantidade de } \\
\text { Unidade Conceitual }\end{array}$ & Percentual (\%) \\
\hline Arte & 47 & 5,043 \\
\hline Atividade do Cotidiano & 137 & 14,912 \\
\hline Biologia & 299 & 32,675 \\
\hline Culinária & 81 & 8,771 \\
\hline Fantástico & 16 & 1,644 \\
\hline Geografia & 45 & 4,824 \\
\hline Linguagem & 250 & 27,302 \\
\hline Matemática & 8 & 0,767 \\
\hline Meio de Transporte & 19 & 1,973 \\
\hline Natureza & 7 & 0,657 \\
\hline Religião & 3 & 0,219 \\
\hline Total & 912 & 100 \\
\hline
\end{tabular}

Fonte: Projeto Resnapap.

\section{TABELA 3}

Conceitos e relações entre os conceitos no sistema de classificação

\begin{tabular}{l|c}
\hline & Total \\
\hline Unidades conceituais no sistema de classificação & 912 \\
\hline Categorias de assunto & 11 \\
\hline Termos relacionados & 33 \\
\hline Termos não-preferidos (remissivas) & 185 \\
\hline
\end{tabular}

Fonte: Projeto Resnapap.

Os fatores que levaram à não-seleção e definição de todos os termos previamente identificados se devem em suma:

- ao fato de que os termos são identificados a priori, mas só serão definitivamente selecionados quando se fizer a definição dos mesmos. A partir da definição é que o conteúdo do termo fica explícito, e é quando se pode fazer uma análise mais segura se o termo identificado é ou não peculiar da cultura amazônica.

- à não-possibilidade de encontrar fontes que contenham informações suficientes para a definição dos termos, quando o autor não deixou explícito o conteúdo dos mesmos no contexto da narrativa.

A partir dos 512 termos culturais, criou-se uma estrutura de classificação na qual se obteve um total de 912 unidades conceituais (tabela 2). Nesse sistema de conceitos, além das 11 Categorias de Assuntos, surgiram também 33 Relações Associativas (Termos Relacionados) e 185 Termos não-preferidos (Termos Equivalentes) (tabela 3).

\section{CONSIDERAÇÕES FINAIS}

Em decorrência de a biblioteconomia e a ciência da informação possuírem essencialmente um caráter interdisciplinar, pôde-se conhecer a rica e fascinante cultura do povo amazônico, cheia de segredos e mistérios, na qual os indivíduos, principalmente do espaço social rural, produzem um ambiente cultural peculiar. É uma das poucas formas culturais que possuem característica própria, fundamentalmente porque nasce em seu próprio bojo e se alimenta do seu próprio meio. Desse modo, alguns estudiosos não receiam em denominar a esse ambiente "cultura amazônica".

Loureiro (2001) afirma que neste ambiente social, sob o ponto de vista global, ainda não houve a ruptura do pensamento mítico para a lógica filosófica comentada por Hegel, ao falar da cultura grega. Por isso, Loureiro (2001) diz que o modo de criação e recriação singular da vida cultural desta região foi se emoldurando por uma espécie de sfumato, onde os habitantes parecem viver em eterno devaneio, tentando explicar o desconhecido através do mito e do imaginário.

Lévi-Strauss (1962) já se preocupava com o tema e previa a perda inexorável da forma original de ser das sociedades que chamou de a-históricas, alertando para o seu fim, visto que, paulatinamente, estas se incorporariam ao que chamou de "sistema mundial". Da mesma forma, Dalcídio Jurandir, pensando na Amazônia, alertou em carta escrita a Maria de Belém Meneses, filha de Bruno de Meneses:

Que a floresta amazônica seja protegida, e os índios também, esse índio ameaçado, em breve expulso do seu chão, massacrado. Belém se cobriu também de sangue de índio, batizou-se nesse sangue. Que o progresso não corra tanto, a ponto de nos tornar, mais depressa, mais infelizes e mais duramente iludidos de que somos civilizados, por bem servidos pela técnica [...] Temo pela descaracterização de Belém, condenada a urbs desumana, poluída, igual a qualquer cidade. Esse progresso desigual faz robots, não cria alma. Aumenta a riqueza e multiplica a necessidade... (JURANDIR, apud MENEZES, 1996, p. 20).

Desse modo, este trabalho se torna imensuravelmente importante, pois, com a elaboração do tesauro, a tendência é divulgar e preservar essa cultura. Principalmente nos dias de hoje, em que há uma cobiça pela floresta amazônica, e o mundo todo, inclusive o próprio Brasil, focaliza o olhar para essa região, em virtude 


\section{Uma estrutura de classificação com enfoque na cultura amazônica}

do seu rico manancial natural, fundamental para o desenvolvimento científico, capitalista, medicinal, tecnológico, entre outros. Nesse sentido, este estudo vem focalizar outro aspecto, o aspecto cultural da vida dos habitantes da região, que vem se transformando de maneira avassaladora.

Artigo recebido em 05/04/2005 e aceito para publicação em 05/01/2006

\section{REFERÊNCIAS}

BARDIN, Laurence. Análise de conteúdo. Tradução de Luiz Antero Reto; Augusto Pinheiro. Lisboa: Edições 70, 1977.

CAMPOS, Maria Luiza de Almeida. A organização de unidades de conhecimento em hiperdocumentos: o modelo conceitual com um espaço comunicacional para realização da autoria. 2001. $171 \mathrm{f}$. Tese (Doutorado em Ciência da Informação) - Escola de Comunicação da Universidade Federal do Rio de Janeiro, Rio de Janeiro, 2001.

; SOUZA, Rosali Fernandez de; CAMPOS, Maria Luiza Machado. Organização de unidades de conhecimento em hiperdocumentos: o modelo conceitual como espaço comunicacional para a realização da autoria. Ciência da Informação, Brasília, v. 32, n. 2, p.7-16, maio/ago. 2003.

DAHLBERG, Ingetraut. Teoria do conceito. Ciência da Informação, Rio de Janeiro, v. 7, n. 2, p. 101-107, 1978.

DEREK, Austin; DALE, Peter. Diretrizes para o estabelecimento e desenvolvimento de tesauros monolíngües. Tradução de Bianca Amaro de Melo. Brasília: IBICT: Senai, 1993. 86 p. Título original: Guidelines for the establishment and development of monolingual thesauri.

FARES, Josebel Akel. Dos campos de cachoeira a Belém do Grão Pará: encontro de vozes em Dalcídio Jurandir. Asas da Palavra, v. 8, n. 17, p. 131-140, jun. 2004.

FAULSTICH, Enilde. Socioterminologia: mais que um método de pesquisa, uma disciplina. Ciência da Informação. Brasília, v. 24, n. 3, p. 281-288, set./ dez. 1995.

GOMES, Hagar Espanha. Classificação, tesauro e terminologia: fundamentos comuns. 1996a. Palestra preparada para as tertúlias do Departamento de Biblioteconomia da UNIRIO. Disponível em: < http: www.conexãorio.com/biti/tertulia/tertulia.htm>. Acesso em: 10 mar. 2003.

Elaboração de tesauro documentário: aspectos teóricos e práticos. Rio de Janeiro: 1996b.

LANGRIDGE, Derek. Classificação: abordagem para estudantes de biblioteconomia. Tradução de Rosali P. Fernandez. Rio de Janeiro: Interciência, 1977. 126 p. Título original: Approach to classification for students of librarianship.

LÉVI-STRAUSS, C. A crise da moderna antropologia. Revista de Antropologia, v. 10, p. 1-2, 1962.
LOUREIRO, João de Jesus Paes. Cultura amazônica: uma poética do imaginário. São Paulo: Escrituras, 2001. 437 p. Originalmente tese de doutorado defendida na Universidade de Sorbonne, Paris, França.

A questão cultural amazônica. In: PARÁ. Secretaria de Estado do Pará. Estudos e problemas amazônicos: história social e econômica e temas especiais. 2. ed. Belém: CEJUP, 1992. 208 p.

MENEZES, Maria de Belém. Um retrato de Dalcídio Jurandir. Asas da Palavra, Belém, v. 3, n. 4, p. 20-26, jun. 1996.

MORIN, Edgar; LE MOIGNE, Jean-Louis. A inteligência da complexidade. São Paulo: Petrópolis, 2000.

NUNES, Benedito. Crônica de Belém: "Belém do Pará". O Estado de São Paulo. Suplemento Literário, v. 5, n. 121, p. 1-3, 25 mar. 1961.

Dalcídio Jurandir: as oscilações de um ciclo romanesco. Asas da Palavra, Belém, v. 8, n. 17, p. 15-21, jun. 2004.

NUNES, Paulo. Aquonarrativa: uma leitura de Chove nos Campos de Cachoeira, de Dalcídio Jurandir. Belém: UNAMA, 2001. 98 p. Originalmente dissertação de mestrado.

Fios mágicos, histórias aquáticas: Dalcídio Jurandir. In: ENCONTRO ABRALIC NA AMAZÔNIA, 2002, Belém. Anais... Belém: UNAMA, 2002. 1 CD-ROM.

OLIVEIRA, Ana Gita de. O mundo transformado: um estudo da "cultura de fronteira" no alto Rio Negro. Belém: Museu Paraense Emílio Goeldi, 1995. 230 p.

OLIVEIRA, Maria Odaisa Espinheiro de; RODRIGUES, Anderson Luiz Cardoso; MOYSÉS, Manoela Ferraz. Classificação dos termos culturais das narrativas marajoaras: uma colaboração para a elaboração de um futuro tesauro cultural amazônico. In: CIBERÉTICA: SIMPÓSIO INTERNACIONAL DE PROPRIEDADE INTELECTUAL, INFORMAÇÃO E ÉTICA, 2., 2003, Florianópolis. Anais eletrônicos... Florianópolis: [s.n.], 2003a. Disponível em: $<$ www.ciberetica.org.br/trabalhos/anais/61-86- c3-1.pdf>. Acesso em: 07 de fev. 2004.

. et al. Vocabulário terminológico: a experiência do projeto RESNAPAP. In: ENCONTRO NACIONAL DE PESQUISA EM CIÊNCIA DA INFORMAÇÃO, 5., 2003, Belo Horizonte. Anais... Belo Horizonte: UFMG, 2003b. 1 CD-ROM.

POMBO, Olga. Da classificação dos seres à classificação dos saberes. Revista da Biblioteca Nacional de Lisboa, Lisboa, n. 2, p. 19-33, primavera 1988.

RANGANATHAN, Shiyali Ramamrita. Prolegomena to library classification. Bombay: Ásia Publishing House, 1967. 640 p.

RODRIGUES, Anderson Luiz Cardoso. Chove nos Campos de cachoeira, de Dalcídio Jurandir e o ciclo da borracha. Asas da Palavra, Belém, v. 8, n. 17, p. 49-55, jun. 2004a.

TORRES, Antônio; MARANHÃO, Haroldo; GALVÃO, Pedro. Um escritor no purgatório. Asas da Palavra. Belém, v. 3, n. 4, p. 28-30, jun. 1996.

TRISTÃO, Ana Maria Delazari; FACHIN, Gleisy Bóries; ALARCON, Orestes Estevam. Sistema de classificação facetada e tesauros: instrumentos para organização do conhecimento. Ciência da Informação, Brasília, v. 33, n. 2, p. 161-171, maio/ago. 2004. 